\title{
Mechanical properties of low-density polyethylene filled by graphite nanoplatelets
}

Carotenuto, G.; De Nicola, S.; Palomba, M.; Pullini, D.; Horsewell, A.; Hansen, Thomas Willum; Nicolais, L.

Published in:

Nanotechnology

Link to article, DOI:

$10.1088 / 0957-4484 / 23 / 48 / 485705$

Publication date:

2012

Document Version

Publisher's PDF, also known as Version of record

Link back to DTU Orbit

Citation $(A P A)$ :

Carotenuto, G., De Nicola, S., Palomba, M., Pullini, D., Horsewell, A., Hansen, T. W., \& Nicolais, L. (2012). Mechanical properties of low-density polyethylene filled by graphite nanoplatelets. Nanotechnology, 23(48), 485705. https://doi.org/10.1088/0957-4484/23/48/485705

\section{General rights}

Copyright and moral rights for the publications made accessible in the public portal are retained by the authors and/or other copyright owners and it is a condition of accessing publications that users recognise and abide by the legal requirements associated with these rights.

- Users may download and print one copy of any publication from the public portal for the purpose of private study or research.

- You may not further distribute the material or use it for any profit-making activity or commercial gain

- You may freely distribute the URL identifying the publication in the public portal 
Mechanical properties of low-density polyethylene filled by graphite nanoplatelets

This article has been downloaded from IOPscience. Please scroll down to see the full text article.

2012 Nanotechnology 23485705

(http://iopscience.iop.org/0957-4484/23/48/485705)

View the table of contents for this issue, or go to the journal homepage for more

Download details:

IP Address: 192.38.67.112

The article was downloaded on 09/11/2012 at 12:18

Please note that terms and conditions apply. 


\title{
Mechanical properties of low-density polyethylene filled by graphite nanoplatelets
}

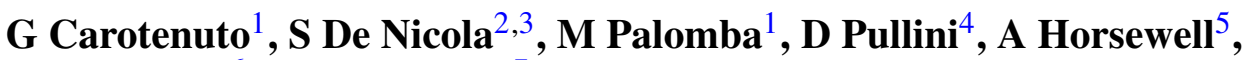 \\ T W Hansen ${ }^{6}$ and L Nicolais ${ }^{7}$ \\ ${ }^{1}$ Institute for Composites and Biomedical Materials, National Research Council, Piazzale Tecchio, 80, \\ I-80125 Napoli, Italy \\ 2 Istituto Nazionale di Ottica, Via Campi Flegrei 34, Pozzuoli, Italy \\ ${ }^{3}$ INFN Sezione di Napoli, Italy \\ ${ }^{4}$ Group Materials Labs, Fiat Research Centre Scpa, Strada Torino 50, I-10043 Orbassano, Italy \\ ${ }^{5}$ Department of Mechanical Engineering and Center for Electron Nanoscopy, Technical University of \\ Denmark, DK-2800 Kongens-Lyngby, Denmark \\ ${ }^{6}$ Center for Electron Nanoscopy, DK-2800 Kongens Lyngby, Denmark \\ ${ }^{7}$ Department of Material Engineering and Production, University 'Federico II' of Naples, \\ Piazzale Tecchio, 80, I-80125 Napoli, Italy
}

E-mail: sergio.denicola@ino.it

Received 1 September 2012, in final form 2 October 2012

Published 6 November 2012

Online at stacks.iop.org/Nano/23/485705

\begin{abstract}
The mechanical properties of GNP/LDPE nanocomposites (graphite nanoplatelets/low density polyethylene) have been investigated, in order to establish the effect of nanoscale reinforcement within the polymer matrix. Results show that the presence of the filler does not involve a change in the microscopic structure of the polymer. However, on a macroscopic scale, GNPs limit the mobility of the polymer chains, resulting in an increase in stiffness for the final composite. Orientation of GNPs within the LDPE matrix is also an important issue that affects mechanical properties and it has been evaluated by testing nanocomposites made by different manufacturing techniques (compression moulding and blown extrusion). The comparison between the experimental data and the Halpin-Tsai model shows that the orientation of GNPs due to the extrusion process leads to values of tensile modulus higher than that obtained with the randomly oriented disposition resulting from the compression moulding technique.
\end{abstract}

(Some figures may appear in colour only in the online journal)

\section{Introduction}

There are different nanostructures which are based on carbon in the $\mathrm{Sp}^{2}$ hybridization form [1]. Fullerenes, carbon nanotubes, graphene and graphene quantum dots are the most common nano-materials containing carbon in the $\mathrm{Sp}^{2}$ (c) (1) Content from this work may be used under the terms ShareAlike 3.0 licence. Any further distribution of this work must maintain attribution to the author(s) and the title of the work, journal citation and DOI. hybridization form, however also graphite nanoplatelets (GNP) and other nanostructures are based on the same kind of carbon. Graphite nanoplatelets are graphite crystals [2] with a thickness of only a few nanometres, whereas the other two dimensions are several hundred microns. These graphite nano-crystals contain only a few (usually less than ten) graphene layers. Graphite nanoplatelets have a semimetallic behaviour, different from graphite which is a metallic material [2] and graphene which is a semiconductor with zero bandgap. Graphene nanoplatelets are usually classified as quasi-bidimensional nanostructures (similarly multi-wall 


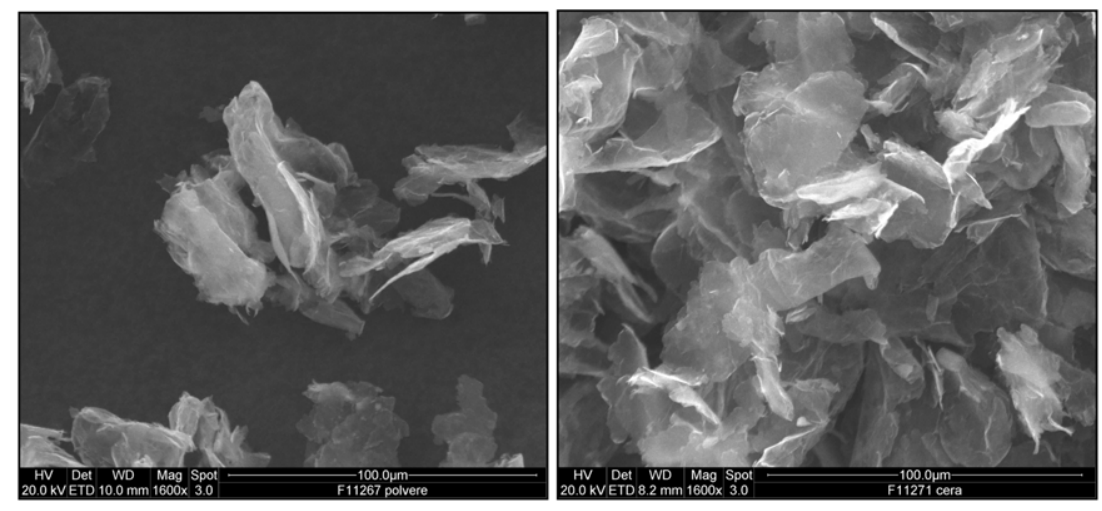

Figure 1. SEM micrographs showing the morphology of graphite nanoplatelets.

carbon nanotubes are considered as quasi-mono-dimensional nanostructures). As visible in the SEM-micrograph shown in figure 1, graphite nanoplatelets are not flat but have a shape twisted like flower petals.

Graphite nanoplatelets can be obtained starting from natural graphite flakes by using a method based on the following three steps [3]: (i) graphite lattice intercalation/oxidation, (ii) graphite lattice expansion by thermal shock, and (iii) exfoliation of the expanded graphite lattice by acoustic energy. In the first step the graphite flakes are chemically treated by an aqueous solution of sulfuric acid $\left(\mathrm{H}_{2} \mathrm{SO}_{4}\right)$ and nitric acid $\left(\mathrm{HNO}_{3}\right)$ at room temperature [4]. Different concentrations of the two acids $\left(\mathrm{H}_{2} \mathrm{SO}_{4} / \mathrm{HNO}_{3}\right.$ ratio of $9: 1$ or $4: 1$ by volume) are used and the reaction time ranges from a few hours to several days. According to the FT-IR analysis of the oxidized material (expandable graphite), only hydroxyl groups are present in the chemically treated crystals and therefore the process should involve only a mild oxidation process. During the thermal expansion stage a small amount of expandable graphite is converted to a large volume of expanded graphite by thermal shock. Different heating approaches can be used, but probably the most convenient one is microwave heating [5]. During this process the oxidized graphite crystals are converted to very porous filaments by an uniaxial expansion mechanism involving the graphite crystal lattice. Such expansion is due to a mixture of gases $\left(\mathrm{CO}_{2}, \mathrm{H}_{2} \mathrm{O}\right.$, and $\left.\mathrm{SO}_{2}\right)$ which are produced in the crystal lattice by the reaction of carbon with $\mathrm{H}_{2} \mathrm{SO}_{4}$ (consequently structural defects appear in the graphite sheets) [6]. Also a dehydration reaction with $\mathrm{H}_{2} \mathrm{O}$ formation is involved in the expansion process. The expansion can be done both in air and under vacuum (or in inert gas), however in air the sample temperature always should be lower than $600^{\circ} \mathrm{C}$ to avoid carbon oxidation, whereas much higher temperatures (e.g., $1500^{\circ} \mathrm{C}$ ) can be reached if the expansion is done under vacuum. In the last step acoustic energy is applied to a liquid dispersion of expanded graphite. The best results are achieved by using horn-sonicators, because much higher power is applied. The different parameters (e.g., time, temperature, power, etc) should be optimized in order to achieve a complete exfoliation of the expanded graphite filaments. To avoid GNP re-aggregation, the dispersing medium must be able to stabilize the surface of these nanostructures [7]; $N$-methyl-pyrrolidone (NMP), dimethylformamide (DMF), and other surface stabilizing molecules give the best results. However, the final GNP thickness depends on the intercalation level: a deep intercalation gives very thin graphite nanoplatelets $(10-20 \mathrm{~nm})$, whereas much thicker nanoplatelets $(80-100 \mathrm{~nm})$ result from a mild intercalation. Depending on the GNP thickness and the type of dispersing medium, stable or unstable GNP colloidal suspensions can be achieved [7]. However, concentrated GNP colloids are always stable, probably because of the random nanoplatelet orientation, which creates a sort of framework that avoids GNP sedimentation [8]. Solvent removal from these concentrated GNP colloidal suspensions generates a sort of GNP aerogel, which is very fragile and can be easily reduced to a redispersible fine powdered product. Such GNP-based material can be redispersed both in liquid solvent and in molten polymers to produce GNP-polymer nanocomposites; alternatively the polymer can be dissolved in the colloid in order to intercalate it before solvent removal [8].

Single-layer graphene has very good mechanical properties (Young's modulus of $1 \mathrm{TPa}$ and tensile strength of $130 \mathrm{GPa}$ ) comparable with values characteristic of carbon nanotubes (tensile strength of 50-150 GPa) and higher than steel (1769 MPa) and Kevlar fibres (3620 MPa). Owing to these excellent mechanical characteristics the use of graphene as reinforcement for polymers has been proposed $[9,10]$. Consequently, also graphite nanoplatelets (a few-layer graphene) could be a convenient reinforcing filler for polymers [10-12]. Similarly to graphite, the non-bonded interactions involved in GNPs are van der Waals forces and consequently the best embedding medium for GNPs are those polymers able to interact by this type of physical bond. Usually, van der Waals forces are involved in polyolefins; consequently, these polymers are good candidates for preparing GNP-based nanocomposites.

Here, low-density polyethylene (LDPE) has been used as a matrix for the GNP-based nanocomposite preparation, the material has been processed in the form of films by compression moulding and blown film extrusion technologies. The obtained films have been morphologically and structurally characterized by transmission electron microscopy (TEM), scanning transmission electron microscopy (STEM), $\mathrm{X}$-ray powder diffraction (XRD), and differential scanning 

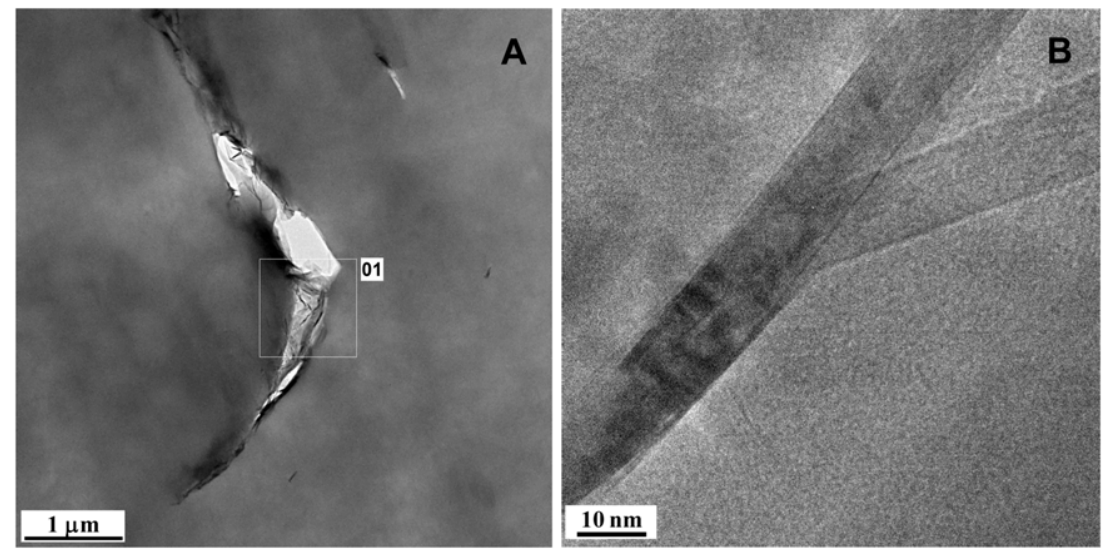

Figure 2. TEM-micrograph of the GNP/LDPE nanocomposite cross-section (A) and high-magnification image $(1000000 \times)$ of the selected area (B).

calorimetry (DSC) in order to establish the characteristics of the GNP embedded in the film and its effect on the LDPE crystallinity. In addition, stress-strain tests have been performed on nanocomposite specimens to evaluate the GNP reinforcement effect.

\section{Experimental part}

GNP/LDPE nanocomposite samples were prepared by using the following method. Small GNP agglomerates were obtained by carefully breaking the fragile structure of the GNP aerogel, which resulted from the drying of a concentrate colloidal suspension (about $33 \mathrm{~g} \mathrm{l}^{-1}$ ) of GNP in acetone. These colloidal GNP suspensions were prepared by exfoliation of expanded graphite using ultrasonication. Both a powerful sonication bath or a sonication horn can be conveniently used, but in order to achieve complete exfoliation, the expanded graphite was gradually added to the colloidal suspension during the sonication treatment. The expanded graphite was obtained by a violent heating of the mild oxidized graphite (expandable graphite). In particular, expandable graphite flakes (Faima, Italy) were placed into a steel crucible covered by a net and allowed to expand in air by applying a thermal shock in a muffle furnace set at $800^{\circ} \mathrm{C}$ (the crucible was abruptly introduced into the oven and the heating time was about $4 \mathrm{~min}$ ). Then, a concentrated GNP/LDPE system (the masterbatch) was prepared and diluted with pure LDPE using a microextruder. In particular, the masterbatch system was prepared by dispersing the expanded graphite in octane $\left(\mathrm{C}_{8} \mathrm{H}_{18}\right.$, Aldrich, 98\%), and intensive sonication was applied to this suspension using a horn-sonicator (Hielshier, $1000 \mathrm{~W}$ ) in order to achieve complete exfoliation of the expanded graphite. The resulting GNP suspension in octane solutions had a characteristic silvery-grey colouration. Then a small amount of LDPE was dissolved into this hydrocarbon GNP suspension at the octane boiling point $\left(104^{\circ} \mathrm{C}\right)$ and the system was slowly concentrated by solvent evaporation. Residual octane was removed by heating small grains of the obtained material under vacuum (oil pump) at a temperature of about $160^{\circ} \mathrm{C}$.

Nanocomposite films were obtained by two different manufacturing techniques: compression moulding and blown extrusion, in order to investigate how the mechanical properties are affected by the orientation of the GNPs within the polymeric matrix. Indeed, because of the irregularity of the nanoplatelets, their orientation inside the LDPE is strongly influenced by the manufacturing process, resulting in a two-dimensional random distribution for the compression moulding and in a more aligned three-dimensional orientation for the blown extruded samples. As a consequence, samples obtained with a blown extrusion will present a high level of anisotropy in comparison with the samples manufactured by compression moulding.

The samples were characterized by transmission electron microscopy (TEM) and scanning transmission electron microscopy (STEM) using a FEI Tecnai G2 with a LaB6 filament operated at $200 \mathrm{kV}$. Samples were prepared by ultramicrotomy and the slices were placed on a standard amorphous carbon film on a copper grid.

To investigate the mechanical characteristics of the GNP/LDPE nanocomposites, film specimens were tested using an Instron 5900. The crosshead speed was set at $100 \mathrm{~mm} \mathrm{~min}^{-1}$ in accordance with EN ISO 527-1:1996 and 10 different specimens were tested for each type of GNP/LDPE nanocomposite composition. DSC measurements have been done by a differential scanning calorimeter (DSC, TA-Instruments Q100).

\section{Results and discussion}

The TEM-micrographs given in figure 2 show the crosssection of the GNP/LDPE nanocomposite. Figure 2(B) is an expanded view of the cross-section shown in figure 2(A), showing the embedded nanoplatelet structure. As visible, the average thickness of the nanoplatelet is about $11 \mathrm{~nm}$. Figure 3 shows two micrographs of the same sample obtained by a scanning transmission electron microscopy (STEM).

In order to investigate the nanocomposite microstructure, $\mathrm{x}$-ray diffraction (XRD) was conducted using $\mathrm{Cu} \mathrm{K} \alpha$ radiation with a wavelength of $1.5406 \AA$. Figure 4 shows the XRD patterns of GNPs-based nanocomposites, with a filler content of $3 \%$ by weight.

The presence of sharp narrow peaks placed on the diffuse halo of amorphous LDPE confirms the semi-crystalline 

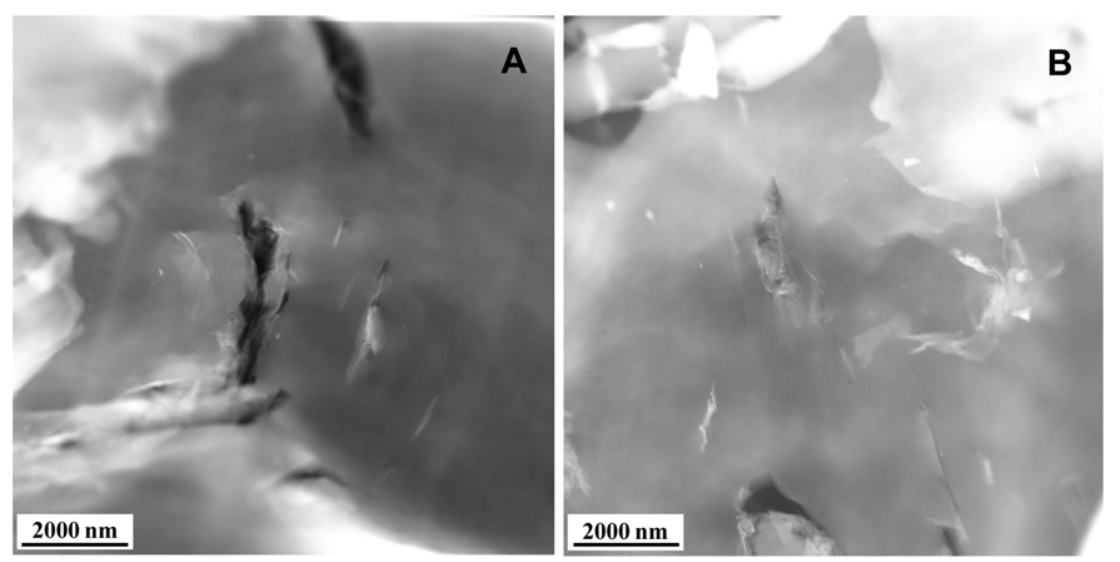

Figure 3. STEM micrographs of the GNP/LDPE nanocomposite cross-section $(6500 \times)$.

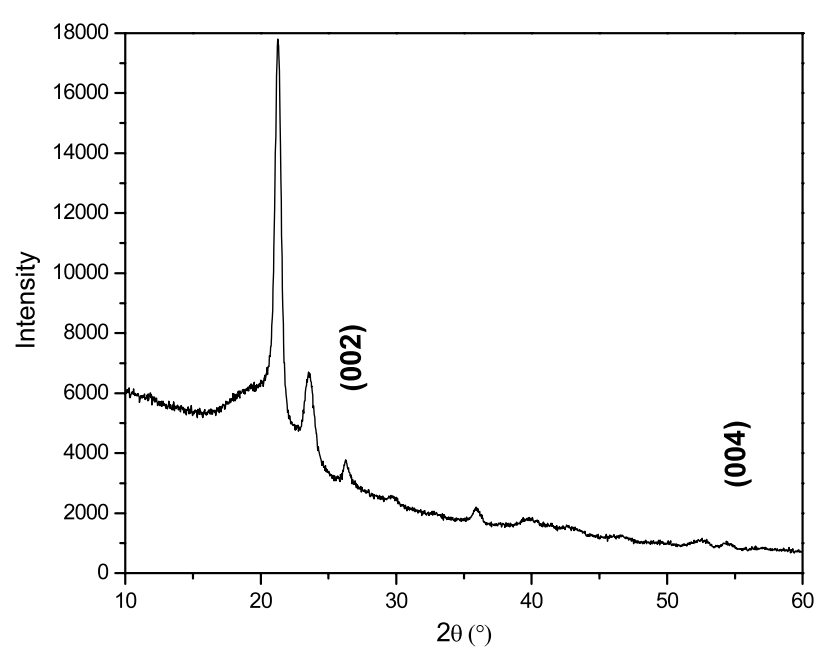

Figure 4. XRD patterns of GNP/LDPE nanocomposites (3\% by weight of GNP).

structure of the embedding LDPE phase. The typical diffraction peaks for LDPE are present in all samples with peaks at $2 \theta$ values of $21.1^{\circ}, 23.8^{\circ}$ and $36^{\circ}$. In addition, it is possible to observe the presence of the (002) peak at $26.5^{\circ}$, which corresponds to a $d$-spacing of $0.335 \mathrm{~nm}$ and is related to the distance between the different layers of the graphite nanoplatelet structure [13-15].

Mechanical properties of a polymer-based nanocomposite are strongly dependent on the amount of crystalline phase in the matrix, therefore, since LDPE is a semi-crystalline material, it is important to establish if the degree of crystallinity is affected by the presence of GNPs. For this reason, DSC analyses were conducted on pure LDPE, and a comparison was made with nanocomposites characterized by an increasing content of filler. Samples weighing about $8 \mathrm{mg}$ were cooled down to $25^{\circ} \mathrm{C}$ and then heated up to $120^{\circ} \mathrm{C}$ at a rate of $10^{\circ} \mathrm{C} \mathrm{min}^{-1}$ under nitrogen atmosphere. The endothermic peak temperature and melting heat acquired from the thermograms are shown in table 1. The percent of crystallinity for all samples was calculated using the equation $W_{\mathrm{c}}^{\mathrm{DSC}}=\Delta H_{\mathrm{f}} / \Delta H^{\circ}$, where $\Delta H_{\mathrm{f}}$ was estimated integrating the melting peak for each sample and $\Delta H^{\circ}$ is the reference
Table 1. Melting temperatures, melting heats, and crystallinity degrees for LDPE and GNP/LDPE nanocomposites.

\begin{tabular}{llll}
\hline Sample & $T_{\mathrm{m}}\left({ }^{\circ} \mathrm{C}\right)$ & $\Delta H_{\mathrm{m}}\left(\mathrm{J} \mathrm{g}^{-1}\right)$ & $W_{\mathrm{c}}^{\mathrm{DSC}}(\%)$ \\
\hline Neat LDPE & 109.6 & 86.4 & 29.5 \\
3\%GNP-LDPE & 109.5 & 84.6 & 28.9 \\
5\%GNP-LDPE & 109.7 & 85.7 & 29.2 \\
\hline
\end{tabular}

melting heat (293.6 $\mathrm{J} \mathrm{g}^{-1}$ ) for polyethylene with $100 \%$ of crystallinity [16].

According to the experimental data given in table 1 , the inclusion of GNPs within the LDPE matrix does not affect polymer crystallinity, and therefore the variation of the nanocomposite mechanical properties cannot be ascribed to a microscopic modification of the polymer structure, but should be related to a macroscopic reinforcement effect due to the presence of the nanoscale filler. Similar crystallinity considerations can be found in the literature for carbon nanotube/polymer and graphene/PVA nanocomposites [17, 18].

To investigate the mechanical behaviour of the GNP/LDPE nanocomposites, tensile tests (stress-strain measurements) were done using film specimens. Figure 5 shows some typical stress-strain curves for LDPE and GNP/LDPE nanocomposites manufactured with compression moulding technique with an increasing percentage of nanoreinforcement (3\% and 5\%). As a consequence of the pressure applied, GNPs are orientated randomly in-plane, leading to an orthotropic material. It is possible to observe that LDPE with a GNPs loading of $3 \%$ shows a $15 \%$ increase in Young's modulus (figure 6), going from $301 \mathrm{MPa}$ of the neat LDPE to $347 \mathrm{MPa}$. Raising the GNPs content up to $5 \%$, the elastic modulus is increased by an additional 16\%, reaching $407 \mathrm{MPa}$. However, as the nanofiller content increases, the maximum strain dramatically decreases from 5.8 to 0.33 , while a slight decrease in maximum stress (from 16 to $12 \mathrm{MPa}$ ) is also observed.

An important observation emerging from the data comparison is that the presence of the GNPs within the LDPE matrix strongly affects the ductility of the neat polymer, shifting the stress-strain curves to a more brittle 


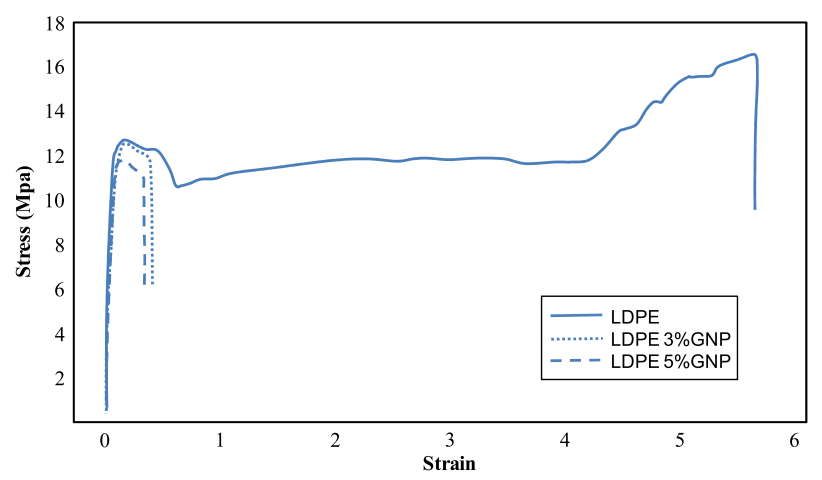

Figure 5. Typical stress-strain curves for neat LDPE and nanocomposites with increasing content of GNPs.

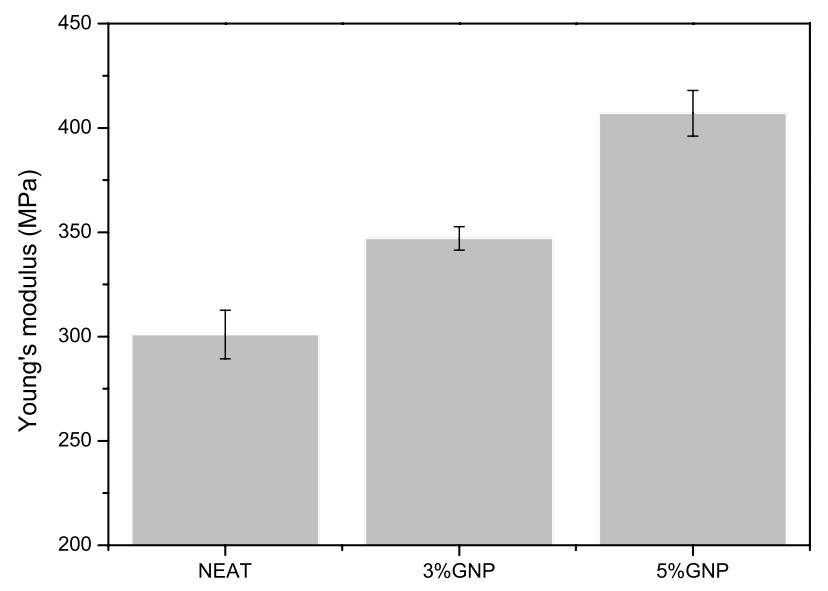

Figure 6. Young's modulus behaviour with increasing percentage of GNP.

behaviour. Indeed, as shown in figure 5, while after yielding LDPE is capable to stand wide extension (up to $600 \%$ ) by activating necking and cold-drawing mechanisms, GNP-based nanocomposites exhibit a very small plastic region (covering strains of $20-30 \%$ ), resulting in an almost brittle fracture right after the yielding point. The reason for this modification could be a reduced polymer mobility due to the presence of GNP. Indeed, the large aspect ratio of the filler and the interaction with the LDPE matrix can obstruct chain movements, resulting in a more brittle material [19]. Moreover, the reduction in tensile strength could be explained with the presence of relatively large inhomogeneities (GNP agglomerates) within the LDPE matrix that leads to structural imperfections able to generate premature cracks [20, 21].

The blown extrusion process leads to nanocomposite films characterized by a high grade of anisotropy. Indeed, because the material is stretched after air injection, GNPs will be oriented in the flow direction, resulting in a material which is characterized by mechanical properties in the machined direction (MD) different from that in the transverse direction (TD).

A first series of mechanical tests were carried out on unreinforced LDPE, and they are shown in figure 7. As visible, in the transverse direction LDPE shows a behaviour which is very similar to that observed for compression

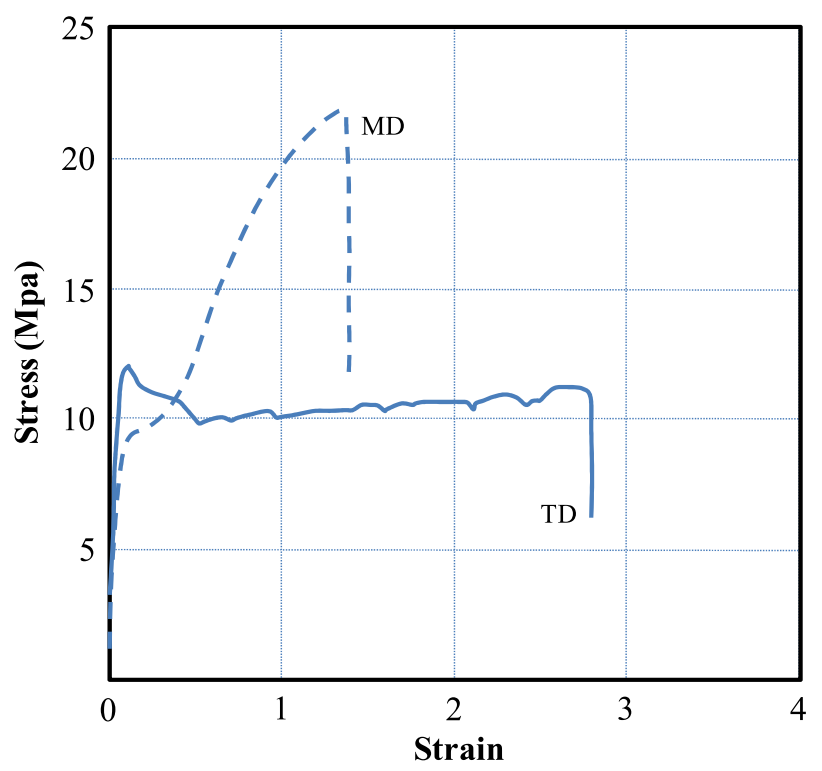

Figure 7. Typical stress-strain curves for neat LDPE in the blown extrusion process.

moulded samples, however the maximum strain reached is only $300 \%$, while it was almost twice that for previously tested LDPE.

The orientation effect of the polymeric chains is clearly visible in the curve for the machined direction (MD) samples, where LDPE acts more like a brittle material, reaching higher values of tensile strength but a lower maximum strain. Similar results have been reported in the literature [22]. Another important consideration concerns the Young's modulus, which is not affected in the passage between the transverse and machined direction (180 MPa for TD and $185 \mathrm{MPa}$ for MD), meaning that the chain orientation affects principally the necking and re-crystallization phases and not the polymer elasticity. In figure 8 it is possible to analyse the stress-strain curves for LDPE nanoreinforced with 5\% wt of GNPs in both the machine and transverse directions.

As for neat LDPE, it is visible the effect produced by the orientation of the graphite nanoplatelets. Indeed, if for the transverse direction the material shows a brittleness similar to that of nanocomposites obtained with compression moulding, in the machined direction the orientation of GNPs leads to higher tensile strength (from 15 to $23 \mathrm{MPa}$ ) and also higher strain (from 0.7 to 1.1). Young's modulus is affected more in the case of the nanocomposite than for the neat polymer, increasing from 430 to $477 \mathrm{MPa}$. This behaviour can be explained on the basis of the presence of oriented GNPs that affect also the elastic behaviour of the nanocomposite, increasing its stiffness, unlike the neat LDPE.

Figure 9 illustrates the curves of comparison for neat LDPE and GNP/LDPE nanocomposites, from which it is possible to analyse how the presence of nanoplatelets affects the mechanical properties of blown extruded film in the transverse and machined direction. Analysing these results it is possible to observe an increase of Young's modulus for both TD (from 180 to $425 \mathrm{MPa}$ ) and MD (from 187 to $477 \mathrm{MPa}$ ) 


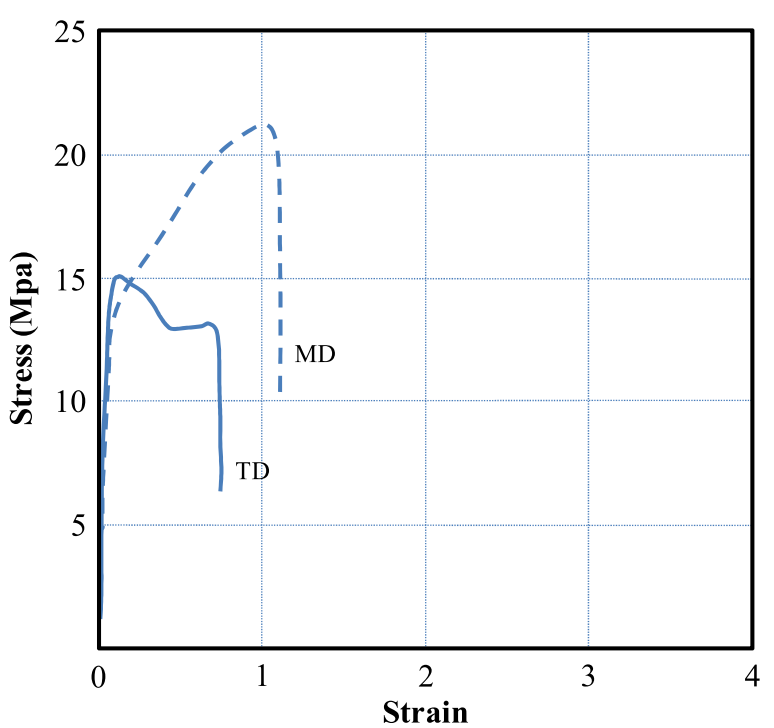

Figure 8. Typical stress-strain curves for GNP/LDPE nanocomposites ( $5 \%$ by weight of GNP) fabricated by the blown extrusion process.

(figure 10), while the maximum strain is reduced by $75 \%$ for TD and by $10 \%$ for MD. However, as for the maximum stress, for TD samples, LDPE filling with GNP leads to an increase of the tensile strength by $30 \%$, while for MD samples it keeps quite constant.

To analyse the obtained mechanical properties we use the Halpin-Tsai model. This model provides a simple approximate form to calculate the modulus of unidirectional or randomly distributed filler-reinforced composites [23-25]. Considering the compression moulded GNP/LDPE samples, the Halpin-Tsai equation is written as follows:

$$
\begin{aligned}
& E_{\text {random }}=E_{\mathrm{p}}\left[\frac{3}{8}\left(\frac{1+(2 a / 3) \eta_{L} V_{\mathrm{G}}}{1-\eta_{L} V_{\mathrm{G}}}\right)\right. \\
& \left.+\frac{5}{8}\left(\frac{1+2 \eta_{T} V_{\mathrm{G}}}{1-\eta_{T} V_{\mathrm{G}}}\right)\right] \\
& E_{\text {Paral }}=E_{\mathrm{p}}\left[\frac{1+(2 a / 3) \eta_{L} V_{\mathrm{G}}}{1-\eta_{L} V_{\mathrm{G}}}\right] \\
& \eta_{L}=\frac{\left(E_{\mathrm{G}} / E_{\mathrm{p}}\right)-1}{E_{\mathrm{G}} / E_{\mathrm{p}}+2 a / 3} \\
& \eta_{T}=\frac{\left(E_{\mathrm{G}} / E_{\mathrm{p}}\right)-1}{E_{\mathrm{G}} / E_{\mathrm{p}}+2}
\end{aligned}
$$

where $E_{\text {random }}$ and $E_{\text {Paral }}$ are the Young's moduli of the composites with randomly oriented GNPs and blown extruded samples with GNPs oriented in the flow direction. $E_{\mathrm{p}}$ and $E_{\mathrm{G}}$ are the tensile modulus of LDPE (taken from the tensile test) and graphene $(\sim 1 \mathrm{TPa})$, the parameter $a$ in equations (1) and (2) is the aspect ratio $a=l_{\mathrm{G}} / t_{\mathrm{G}}$, with $l_{\mathrm{G}}$ the length of one GNP, and $t_{\mathrm{G}}$ its thickness. $V_{\mathrm{G}}$ is the volume fraction of the nanoreinforcement. The mass fraction $w(\mathrm{wt} \%)$ can be converted to the volume fraction $V_{\mathrm{G}}$ by the following
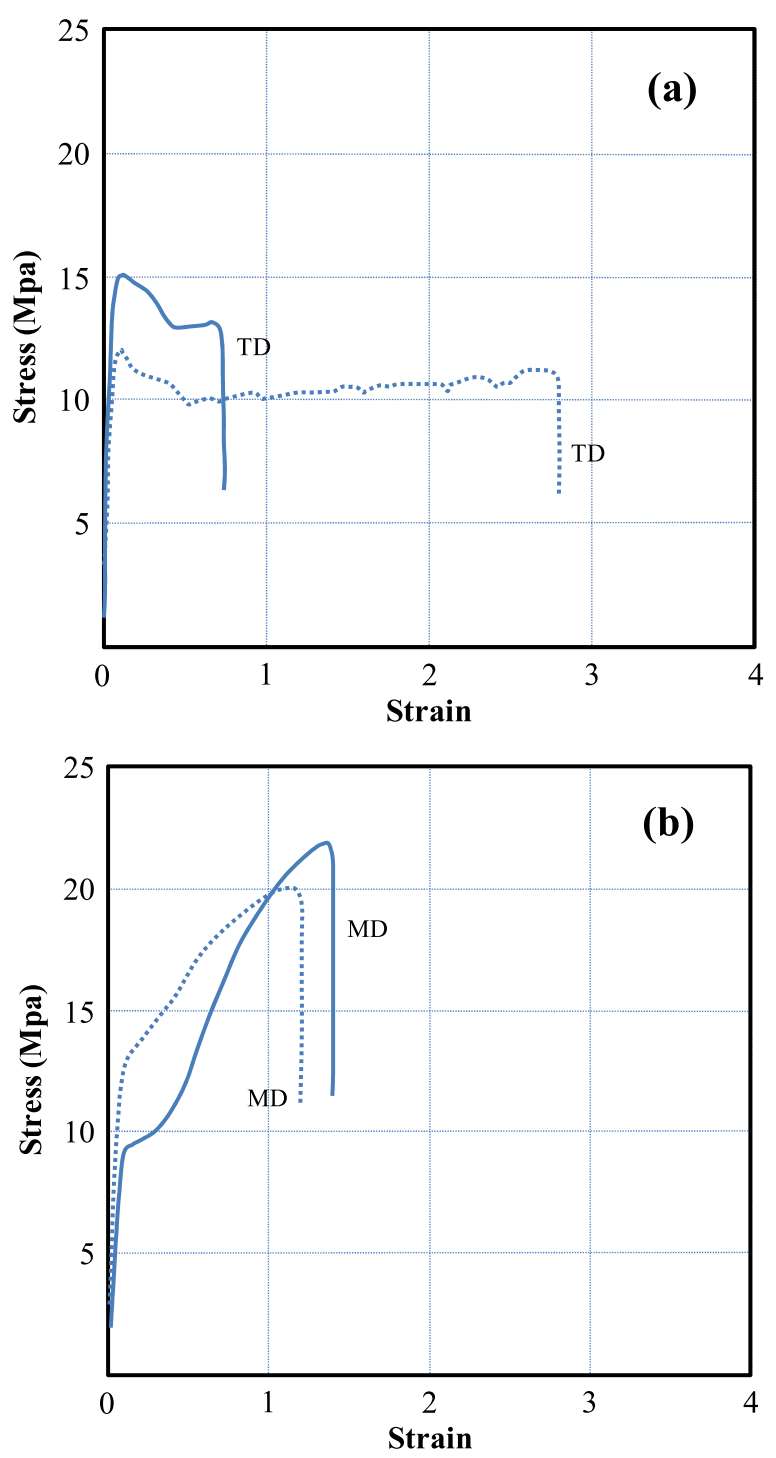

Figure 9. Comparison between stress-strain curves for GNP/LDPE nanocomposites (5\% by weight of GNP) and neat LDPE in the transverse (a) and machined (b) directions.

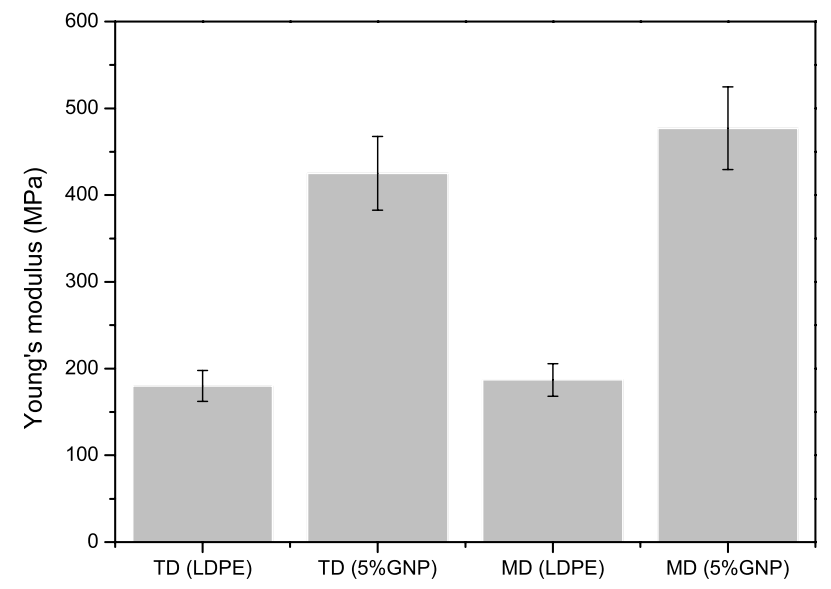

Figure 10. Young's modulus increase for GNP/LDPE in both the transverse and machined direction. 


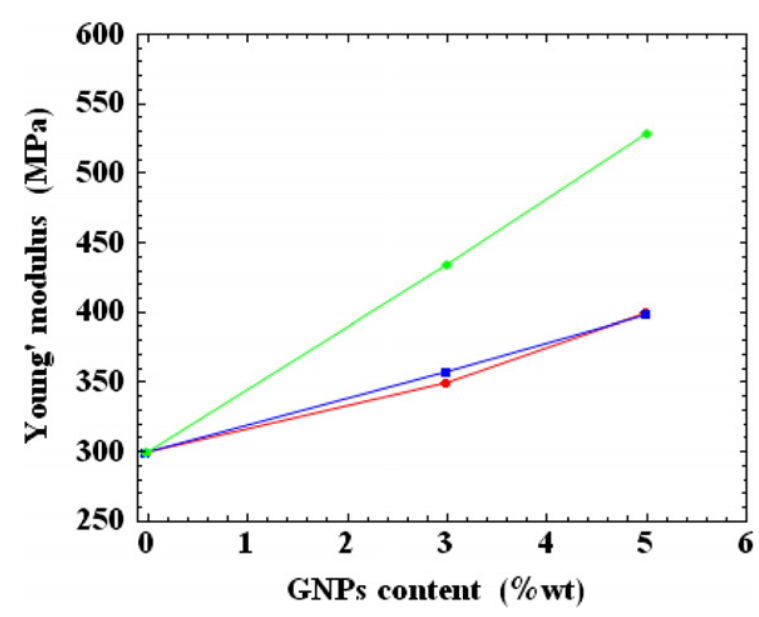

Figure 11. Comparison between the Halpin-Tsai modulus evaluation model and experimental data for compression moulded GNP/LDPE nanocomposites: experimental data (red curve); Halpin-Tsai model of unidirectional distribution of GNPs (green curve); Halpin-Tsai model of randomly orientated GNPs (blue curve).

equation:

$$
V_{\mathrm{G}}=\frac{w \rho_{\mathrm{p}}}{w \rho_{\mathrm{p}}+(1-w) \rho_{\mathrm{G}}} .
$$

Here, $\rho_{\mathrm{p}}$ and $\rho_{\mathrm{G}}$ represent the density of the LDPE matrix and graphene nanosheets, which can be taken as $0.940 \mathrm{~g} \mathrm{~cm}^{-3}$ and $2.2 \mathrm{~g} \mathrm{~cm}^{-3}$, respectively. Figure 11 shows the experimental data of Young's modulus for compression moulded GNP/LDPE nanocomposites. The trend of the modulus with graphene loading (red curve) is compared with the theoretical prediction of the Halpin-Tsai model.

The theoretical simulations were taken as two cases: a random orientation of GNPs in the polymer matrix (blue curve) and a unidirectional distribution of graphene nanosheets (green curve). The length of one GNP and its thickness were taken as $\sim 1 \mu \mathrm{m}$ and $\sim 20 \mathrm{~nm}$, respectively $(a=50)$. The comparison between the experimental results in figure 11 and the theoretical predictions indicates that graphene nanosheets are randomly dispersed in the LDPE matrix and that the addition of GNPs leads to an enhancement of the composite mechanical properties, illustrating how the experimental data match the theoretical model. For blown extruded samples GNPs are oriented in the flow direction, and figure 12 shows the comparison between the theoretical model given by equations (2) and (3) and the experimental data for the blown extruded GNP/LDPE nanocomposites.

Figure 12 shows the comparison between the theoretical model and the experimental data for the blown extruded GNP/LDPE nanocomposites. As it is possible to observe from the curves, the experimental value of Young's modulus for the nanocomposites is higher than the one predicted by the Halpin-Tsai equation (blue curve) by almost $50 \%$. One possible explanation for this behaviour could be found in the dimensions of the nanoplatelets after the manufacturing process. Indeed, during the extrusion process, GNPs are strongly stretched in the machine direction, therefore, because

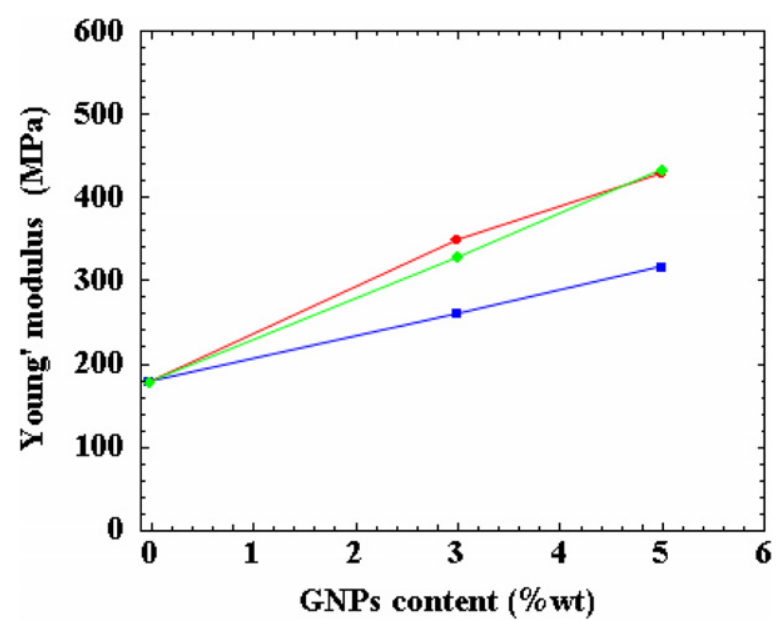

Figure 12. Comparison between the Halpin-Tsai modulus evaluation model and experimental data for blown extruded GNP/LDPE nanocomposites: experimental data (red curve); Halpin-Tsai model of unidirectional distributed GNPs: GNP thickness of $20 \mathrm{~nm}$ (blue curve); GNP thickness of $18.2 \mathrm{~nm}$ (green curve).

the different graphene layers are bonded together only by weak van der Waals forces, this stretching effect could lead to a thinning of the graphite nanoplatelets. This thickness reduction is confirmed by fitting the experimental data with the theoretical curve (green curve) calculated for a GNP thickness $t_{\mathrm{G}}=18.2 \mathrm{~nm}$, corresponding to a $10 \%$ increase in the aspect ratio for blown extruded GNP/LDPE compared to compression moulded GNP/LDPE nanocomposites.

\section{Conclusion}

We have described and discussed a masterbatch approach that allows one to prepare very homogeneous GNP/LDPE nanocomposites. Such material can be processed in the form of films by compression moulding and blown extrusion technologies to obtain a system characterized by a significant iso-orientation of the GNP units. Filling low-density polyethylene by graphite nanoplatelets results in an increase of the Young's modulus of the neat LDPE and a reduction of the polymer plasticity. Brittle GNP/LDPE films characterized by lower fracture stress values are obtained by both compression moulding and blown extrusion technologies. According to the DSC investigation, such mechanical behaviour is not caused by a variation in the polymer crystallinity but rather by the absence of cold-drawing mechanism, probably due to the GNP presence that acts to reduce the mobility of polymer chains. The decrease of mechanical resistance can be ascribed to the presence of GNP aggregates inside the polymer matrix. Since the only physical interactions at the GNP-LDPE interface are those caused by van der Waals forces, nanocomposite samples show a brittle behaviour because of crack-propagation phenomena. However, it is worth pointing out that the nanocomposite interfacial properties might be improved by establishing chemical bonds between GNP and LDPE, for example, by introducing compatibilizing agents in the system (e.g., 
polyethylene grafting agents such as maleic anhydride). In fact, free radical addition to the carbon-carbon double bonds at graphite nano-crystal edges should be a very favoured chemical reaction.

\section{Acknowledgments}

The A P Møller and Chastine Mc-Kinney Møller Foundation is gratefully acknowledged for their contribution towards the establishment of the Center for Electron Nanoscopy in the Technical University of Denmark.

\section{References}

[1] Suarez-Martinez I, Grobert N and Ewels C P 2012 Carbon 50741

[2] Chung D D L 2002 J. Mater. Sci. 371475

[3] Geng Y, Wang S J and Kim J-K 2009 J. Colloid Interface Sci. 336592

[4] Afanasov I M, Shornikova O N, Kirilenko D A, Vlasov I I, Zhang L, Verbeeck J, Avdeev V V and Van Tendeloo G 2010 Carbon 481858

[5] Kwon O Y, Choi S W, Park K and Kwon Y B 2003 J. Ind. Eng. Chem. 9743

[6] Gui-Lei S, Xiao-Jie L and Hong-Hao Y 2007 New Carbon Mater. 22242

[7] Wei T, Fan Z, Luo G, Wang S and Song L 2009 Mater. Res. Bull. 44977

[8] Lin C and Chung D D L 2009 Carbon 47295

[9] Li B and Zhong W-H 2011 J. Mater. Sci. 465595
[10] Delgado-Rangel J-A, Addiego F, Eddoumy F, Ahzi S, Patlazhan S, Toniazzo V and Ruch D 2012 J. Appl. Polym. Sci. 1254316

[11] Li J, Kim J-K and Sham M L 2005 Scr. Mater. 53235

[12] Raza M A, Westwood A, Brown A, Hondow N and Stirling C 2011 Carbon 494269

[13] Lian P, Zhu X, Liang S, Li Z, Yang W and Wang H 2010 Electrochim. Acta $\mathbf{5 5} 3909$

[14] Yang J, Zhang L Q, Shi J H, Quan Y N, Wang L L and Tian M 2010 J. Appl. Polym. Sci. 1162706

[15] George J J, Bandyopadhyay A and Bhowmick A K 2008 J. Appl. Polym. Sci. 1081603

[16] Morawiec J, Pawlak A, Slouf M, Galeski A, Piorkowska E and Krasnikowa N 2005 Eur. Polym. J. 411115

[17] Liu L, Barber A H, Nuriel S and Wagner H D 2005 Adv. Funct. Mater. 15975

[18] Liang J, Huang Y, Zhang L, Wang Y, Ma Y, Guo T and Chen Y 2009 Adv. Funct. Mater. 192297

[19] Kuilla T, Bhadra S, Yao D, Kim N H, Bose S and Lee J H 2010 Prog. Polym. Sci. 351350

[20] Zheng W, Lu X and Wong S-C 2004 J. Appl. Polym. Sci. 912781

[21] Andrews R, Jacques D, Minot M and Rantell T 2002 Macromol. Mater. Eng. 287395

[22] Guichon O, Séguéla R, David L and Vigier G 2003 J. Polym. Sci. B 41327

[23] Zhou T, Chen F, Tang C, Bai H, Zhang Q, Deng H and Fu Q 2011 Compos. Sci. Technol. 711266

[24] Liang J, Huang Y, Zhang L, Wang Y, Ma Y, Guo T and Chen Y 2009 Adv. Funct. Mater. 192297

[25] Zhao X, Zhang Q, Chen D and Lu P 2010 Macromolecules 432357 